\title{
Multiple foraging strategies in a marine apex predator, the Galapagos sea lion Zalophus wollebaeki
}

\author{
Stella Villegas-Amtmann ${ }^{1, *}$, Daniel P. Costa ${ }^{1}$, Yann Tremblay ${ }^{1}$, \\ Sandie Salazar ${ }^{2,3}$, David Aurioles-Gamboa ${ }^{2}$ \\ ${ }^{1}$ Department of Ecology and Evolutionary Biology, Long Marine Laboratory, 100 Shaffer Road, \\ University of California Santa Cruz, Santa Cruz, California 95060, USA \\ ${ }^{2}$ Centro Interdisciplinario de Ciencias Marinas, IPN, La Paz, Baja California Sur, Mexico \\ ${ }^{3}$ Charles Darwin Foundation, Puerto Ayora, Galapagos, Ecuador
}

\begin{abstract}
Three fundamental foraging patterns in air-breathing marine vertebrates have been described: epipelagic, mesopelagic and benthic. Many sea lion species with access to extensive continental shelves have been described as benthic foragers. Coincidently these species are considered threatened. The Galapagos sea lion Zalophus wollebaeki, a top predator in the Galapagos Islands, is also considered threatened in this ecosystem. Sea lions at the central part of the archipelago have access to a vast continental shelf. For this reason we hypothesized that sea lions within this region would dive benthically. In addition, effective protection and conservation of this species requires knowledge of their foraging patterns and habitat utilization. We investigated the diving behaviour and habitat utilization of female $Z$. wollebaeki of a centrally located colony situated inside the highest density area of the population using time-depth recorders and satellite telemetry. Three distinct foraging patterns were found and described (shallow, deep and bottom divers), and individuals utilizing each pattern foraged in different locations. Epipelagic, mesopelagic and benthic dives were exhibited in the sea lions' diving behaviour, but these dive types were not exclusively associated with a foraging pattern. Between foraging trips females hauled out more frequently on other islands than they did on their breeding colony. The finding of 3 distinct foraging patterns that differ spatially has direct implications for management, particularly with regard to fisheries interactions. Marine protected areas can be implemented in the regions described as $Z$. wollebaeki foraging areas. $Z$. wollebaeki's wide foraging range coupled with their use of multiple haul-out sites should be considered in future studies when determining foraging trip lengths and habitat utilization since presence/absence from the colony does not reflect foraging trip length.
\end{abstract}

KEY WORDS: Diving behaviour - Foraging behaviour - Galapagos Islands · Habitat utilization Individual specialization · Galapagos sea lion · Zalophus wollebaeki

Resale or republication not permitted without written consent of the publisher

\section{INTRODUCTION}

Foraging patterns of air-breathing marine vertebrates may be classified by the habitats in which individual species forage. Epipelagic and mesopelagic foragers utilize the water column between $0-200$ and 200-1000 m respectively; benthic foragers use the sea floor (Tremblay \& Cherel 2000, Costa \& Gales 2003). Epipelagic foragers include Antarctic fur seals Arcto- cephallus gazella (Boyd \& Croxall 1992), California sea lions Zalophus californianus (Feldkamp et al. 1989) and leatherback turtles Dermochelys coriacea (Eckert 2006). Among mesopelagic foragers are king penguins Aptenodytes patagonicus and northern elephant seals Mirounga angustirostris (LeBoeuf et al. 1986, Kooyman et al. 1992). Benthic foragers include pinnipeds such as Australian (Neophoca cinerea), New Zealand (Phocarctos hookeri) and Southern (Otaria flavescens) sea 
lions, sea turtles like loggerhead Caretta caretta and olive ridley Lepidochelys olivacea and seabirds such as cormorants (Phalacrocoracidae) (Cooper 1986, Thompson et al. 1998, Costa \& Gales 2000, 2003, HopkinsMurphy et al. 2003, McMahon et al. 2007). Diving patterns have been described for all extant sea lion species (Kooyman \& Trillmich 1986, Feldkamp et al. 1989, Merrick \& Loughlin 1997, Thompson et al. 1998, Costa \& Gales 2000, 2003). However, diving behaviour of the Galapagos sea lion Zalophus wollebaeki has been investigated in only 4 individuals (Kooyman \& Trillmich 1986).

Zalophus wollebaeki is endemic to the Galapagos Islands. The population is widely distributed among this archipelago, with the highest density of individuals at the central and southern islands (Salazar 2005). Current population estimates lie between 16000 and 18000 individuals (Salazar 2005) although an estimate of 20000 to 50000 individuals in 1963 suggests a dramatic decline in the population over the last $20 \mathrm{yr}$. (Heath 2002). The population fluctuates in size and is negatively affected by El Niño events (Trillmich \& Limberger 1985).

The breeding season is protracted in Zalophus wollebaeki compared to other sea lion species. Births occur from June to March, but the peak pupping period varies among rookeries and years. Pups are weaned at a time when they are independently foraging-usually around 2 to 3 yr old (Trillmich 1986, Heath 2002).

Prey species found in the diet of Zalophus wollebaeki from multiple colonies include epipelagic fish (Clupeidae) of surface and coastal upwelling waters, mesopelagic fish (Myctophidae) found in deep waters of the open ocean, and demersal, benthopelagic or pelagic fish (Chlorophtalmidae, Serranidae and Mugilidae) found over muddy and sandy bottoms of the continental shelf or in shallow and deep waters between rocks (Salazar 2005, Froese \& Pauly 2006).

Further, Zalophus wollebaeki provide an important ecosystem function as transporters of marine nutrients to terrestrial habitats of the Galapagos Islands (Fariña et al. 2003). Despite their vulnerability (Seal Specialist Group 1996) and importance, very little is known about the marine habitat utilization of these sea lions. The diving behaviour of this species was studied only once previously (Kooyman \& Trillmich 1986) and at a different site, during a different time and with about half the number of individuals as the present study.

We investigated the diving behaviour and spatial habitat utilization of lactating female Zalophus wollebaeki at Caamaño Islet, south of Santa Cruz Island in the Galapagos Islands. The islet is characterized by an extensive continental shelf and access to a broad central underwater plateau. Pinniped species inhabiting similar bathymetric conditions (e.g. Australian, New Zealand and Southern sea lions) are described as benthic foragers (Thompson et al. 1998, Costa \& Gales 2000, 2003). Although some epipelagic and mesopelagic fish have been found in the $Z$. wollebaeki diet, we hypothesized that sea lions in this colony would dive predominantly benthically based on Caamaño Islet bathymetric conditions. Our objectives were to detail the at-sea habitat utilization and foraging behaviour of $Z$. wollebaeki centrally located within their range and to provide valuable data for conservation and protection measures.

\section{MATERIALS AND METHODS}

Field site and general procedures. During March 2005 we captured 9 lactating female Galapagos sea lions Zalophus wollebaeki, which were suckling small pups 4 to 5 mo after peak pupping season at Caamaño Islet $\left(0.759^{\circ} \mathrm{S}, 90.278^{\circ} \mathrm{W}\right)$ in the Galapagos Islands. Caamaño Islet holds a population of approximately 970 individuals, and, together with Santa Cruz Island, represents the second largest colony: $14 \%$ of the total population (Salazar 2005, Wolf \& Trillmich 2007). Sea lions were captured with hoop nets and anesthetized with isoflurane gas (0.5 to $2.5 \%)$ with oxygen via a portable field vaporizer, administered through a cone shaped mask and then with an endotracheal tube (Gales \& Mattlin 1997). Individuals were instrumented with SPOT4 satellite platform terminal transmitters (PTT) (Wildlife Computers) for large-scale tracking, time-depth recorders (TDR) (2 Mk6, 2 Mk8 and 5 Mk9 models, Wildlife Computers) to obtain diving behaviour data, and radio transmitters (VHF, Sirtrack) to locate the sea lions for instrument recovery when on land. We mounted instruments on mesh netting and glued them to the dorsal pelage of the lower back and between the shoulders of the sea lions using $5 \mathrm{~min}$ quick set Loctite epoxy. The total weight of the attached instruments was $230 \mathrm{~g}$ (approximately $0.23 \%$ of the sea lions' mass). We weighed sea lions in a sling using a tripod and a $250 \mathrm{~kg}( \pm 0.1 \mathrm{~kg}$ precision) capacity digital scale. We recaptured all the sea lions after 7 to $11 \mathrm{~d}$. The equipment was removed by physically restraining individuals without anesthesia. Epoxy mounts fall off within a few months during the sea lions' annual moult.

Tracking data analysis. To determine the sea lions' habitat utilization and foraging range we used a program from the IKNOS toolbox (custom software developed by Y. Tremblay) to filter satellite location data obtained through ARGOS. The algorithm uses several criteria to remove unlikely locations: (1) realistic travel speeds of a subject between 2 fixes $\left(\geq 10 \mathrm{~km} \mathrm{~h}^{-1}\right)$, 
(2) change in azimuth between successive fixes, (3) Argos location class and (4) time lapse between 2 consecutive fixes. We plotted filtered locations on a map in Matlab (The MathWorks).

Diving behaviour data analyses. We analysed dive data in Matlab using a custom-written dive analysis program (Y. Tremblay unpubl. data) which allows for a zero offset correction at the surface and the identification of dives based on a minimum depth and duration. All Mk9 and Mk8 recorders had a $0.5 \mathrm{~m}$ depth resolution and sampled every $2 \mathrm{~s}$. One Mk6 had a $2 \mathrm{~m}$ resolution and the other a $4 \mathrm{~m}$ resolution; both sampled every $4 \mathrm{~s}$. The minimum depth for a dive was set at 5, 6 or $8 \mathrm{~m}$, depending on the sampling depth resolution of the TDR used $(0.5,2$ or $4 \mathrm{~m}$ respectively). These depths accounted for instrument error while detecting the minimum depths possible by the dive analysis program. The minimum duration for a dive was set at $12 \mathrm{~s}$ to standardize the different sampling intervals of the tags ( 2 and $4 \mathrm{~s}$ ) and by setting a minimum of 3 sampling points for dive identification by the dive analysis program.

Sea lions exhibit characteristic sequences of shallow dives when travelling to different locations; this behaviour has been described as 'porpoising' (Blake 1983, Williams 2001). The depth of these shallow dives peaks on a frequency distribution diagram of maximum dive depths (Tremblay \& Cherel 2003), making porpoising depth evident. Following similar procedures as in Tremblay \& Cherel (2003), porpoising dives in our data were restricted to the upper 10 to $12 \mathrm{~m}$ and were discarded from the analysis because their recognition was dependent on the type of recorder used. By eliminating these porpoising dives we also limited the effects of the dissimilarity in sampling resolution between the different recorders used. This was consistent with our goal of analysing potential foraging dives (i.e. feeding or search dives).

We conducted multivariate analyses in SYSTAT 10.2 to classify diving behaviour. Data were tested for normality by visual examination of probability plots and no transformations were needed. Results presented are means $\pm 1 \mathrm{SD}$. Variables used are averages of the following for each dive: maximum depth (m), dive duration (s), bottom time (s), number of 'wiggles' at the bottom of a dive (number of ascent and descent movements at the bottom of the dive, which can imply foraging behaviour; Kuhn 2006), descent and ascent rate $\left(\mathrm{m} \mathrm{s}^{-1}\right)$, dive rate $\left(\right.$ dives $\left.\mathrm{h}^{-1}\right)$ and mass $(\mathrm{kg})$.

Principal component analysis (PCA) was used to reduce the number of variables, followed by a hierarchical cluster analysis (HCA) to classify diving behaviour. We used Latent root criterion, a minimum Eigen value of 1.0 and a varimax rotation for the PCA. This analysis is suitable for this type of data because the diving variables are strongly correlated (McGarigal et al. 2000). Standardized PCA factor scores were input as variables in the HCA, which we conducted using Euclidean distance and average linking method. Hierarchical clustering is ideal for small data sets as in this study (McGarigal et al. 2000).

To further characterize diving behaviour, we used the intra-depth zone (IDZ) (Tremblay \& Cherel 2003). IDZ provides an index of the tendency to repeatedly dive to a given depth. An IDZ of 1 indicates a maximum dive depth is within a user-defined zone of the maximum depth of the previous dive. An IDZ of 0 means a dive does not fall within the maximum depth of the previous dive. Considering that $4 \mathrm{~m}$ was the lowest depth resolution of the instruments, we applied a user-defined zone of $\pm 10 \mathrm{~m}$ of the maximum depth of the previous dive (i.e. $5 \mathrm{~m}$ above or below the previous depth).

\section{RESULTS}

\section{Habitat utilization and foraging trips}

Satellite tracking duration varied from 8 to $11 \mathrm{~d}$ $($ mean $=8.55 \pm 1.13 \mathrm{~d})$, generating $28.8 \pm 4.2($ range $=$ 24-36) filtered satellite locations for each female, $71.5 \pm 17.9 \%$ of which were at sea. TDR deployment duration also varied from 8 to $11 \mathrm{~d}$, with data collected over a mean of $9.29 \pm 0.89$ d. Females performed $6.22 \pm$ 2.16 unique trips to sea ( 4 to 10 trips, $\mathrm{N}=9$ females), spending $59 \pm 11 \%$ of their time at sea. Average maximum distance recorded from the rookery per female was $41.76 \pm 20.27 \mathrm{~km}$ (range: 14.3 to $76 \mathrm{~km}$ ) (Table 1) Females hauled out at islands other than their breeding colony $79 \%$ of the time (3 to 9 haul-out periods recorded per sea lion, $\mathrm{N}=48$ ). They used 9 haul-out areas in addition to the Caamaño Islet rookery, which was used only $21 \%$ of the total haul-out time (Fig. 1). Foraging trips (time at sea between haul-out periods) lasted $23.87 \pm 11.03 \mathrm{~h}$ on average $(\mathrm{N}=9$ females $)$ (range $=7.5 \mathrm{~h}$ to $4.9 \mathrm{~d}, \mathrm{~N}=56 \mathrm{trips}$ ). Haul-out times between foraging trips ranged between 1.12 and $35.5 \mathrm{~h}$ ( $\mathrm{N}=47$ haul-out periods) with a mean of $11.9 \pm$ $2.9 \mathrm{~h}$ ( $\mathrm{N}=9$ females). Trip durations from the rookery, or the time away from their pups, ranged between $9.1 \mathrm{~h}$ and $9.13 \mathrm{~d}(\mathrm{~N}=19$ trips from rookery), with a mean duration of $4.18 \pm 2.06 \mathrm{~d}$ (mean range $=1.3$ to $8 \mathrm{~d}$, $\mathrm{N}=9$ females). Although females tended to repeatedly haul out at the same sites (other than their breeding rookery), they also visited different haul-out sites during different foraging trips. Females showed preferences in their haul-out behaviour: some individuals hauled out at night, some during the day, and others during the day and at night. 
Table 1. Zalophus wollebaeki. Female trip durations from time-depth recorder (TDR) records (mean \pm SD) between haul-out periods (mean trip duration) and between haul-outs at the rookery (mean trip duration from rookery). Caamaño Islet, March 2005

\begin{tabular}{|c|c|c|c|c|c|c|c|c|c|}
\hline $\begin{array}{l}\text { Female } \\
\text { ID }\end{array}$ & $\begin{array}{l}\text { \# Foraging } \\
\text { trips } \\
\text { recorded }\end{array}$ & $\begin{array}{l}\text { Mean trip } \\
\text { duration } \\
\text { (h) }\end{array}$ & $\begin{array}{l}\text { \# Foraging } \\
\text { trips from } \\
\text { rookery }\end{array}$ & $\begin{array}{l}\text { Mean trip } \\
\text { duration from } \\
\text { rookery (h) }\end{array}$ & $\begin{array}{c}\text { Mean } \\
\text { haul-out } \\
\text { duration (h) }\end{array}$ & $\begin{array}{l}\text { \# Haul-out } \\
\text { periods } \\
\text { recorded }\end{array}$ & $\begin{array}{c}\text { Total \# } \\
\text { days } \\
\text { recorded }\end{array}$ & $\begin{array}{l}\text { Max. dist. } \\
\text { traveled from } \\
\text { rookery }(\mathrm{km})\end{array}$ & $\begin{array}{l}\text { \# Haul-out sites } \\
\text { used (including } \\
\text { rookery) }\end{array}$ \\
\hline CAAF02 & 5 & $40.2 \pm 45.5$ & 3 & $81.3 \pm 119.4$ & $17.4 \pm 15.7$ & 4 & 11.3 & 54.2 & 3 \\
\hline CAAF03 & 6 & $24.4 \pm 13.4$ & 2 & $89.2 \pm 39.4$ & $13.4 \pm 12.4$ & 5 & 9.4 & 54.2 & 3 \\
\hline CAAF05 & 10 & $12 \pm 1.9$ & 3 & $62.3 \pm 58.7$ & $9.9 \pm 3.8$ & 9 & 9.5 & 43 & 2 \\
\hline CAAF09 & 4 & $32.1 \pm 25.9$ & 4 & $32.1 \pm 25.9$ & $10.6 \pm 0.2$ & 3 & 9.2 & 23.5 & 1 \\
\hline CAAF10 & 4 & $35.4 \pm 26.6$ & 2 & $77.5 \pm 7.4$ & $16 \pm 16.5$ & 3 & 8.7 & 55.2 & 2 \\
\hline CAAF11 & 7 & $19.3 \pm 11.4$ & 1 & 191.5 & $9.3 \pm 1.5$ & 6 & 8.6 & 76.2 & 2 \\
\hline
\end{tabular}

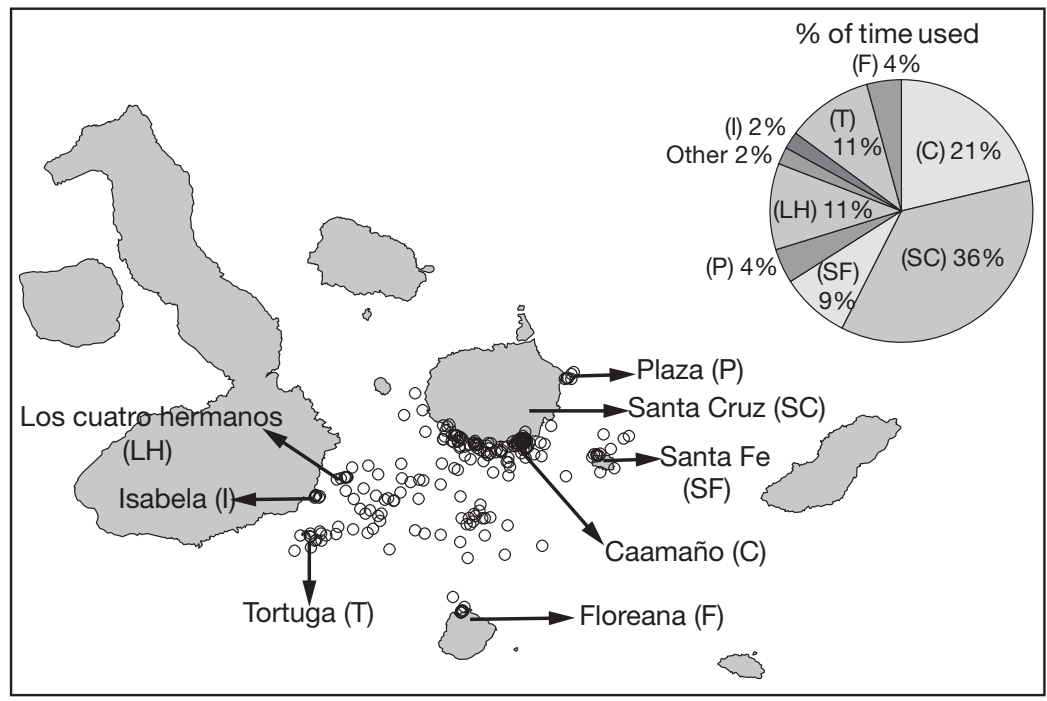

Fig. 1. Zalophus wollebaeki. Locations of alternate haul-out sites used by 9 females from Caamaño Islet, March 2005. Pie chart indicates percentage of the total number of haul-outs at these alternate sites

\section{Diving behaviour and foraging strategies}

Elimination of travelling dives resulted in the analysis of $997 \pm 293$ (range $=595$ to 1636 ) dives per female, accounting for 62.46 to $100 \%$ of the total number of dives. One female (CAAF08) showed no travel dives and foraged coastally around the rookery.

At sea, females spent $53 \pm 14 \%$ of their time diving. Mean individual dive depth ranged from 45 to $149 \mathrm{~m}$ and averaged $91.8 \pm 35.2 \mathrm{~m}(\mathrm{~N}=9)$. Mean individual dive durations ranged from 2.9 to $5.8 \mathrm{~min}$, with an average of $4.0 \pm 0.9 \mathrm{~min}(\mathrm{~N}=9$ ) (Table 2). Sea lions also varied in the time of day they dived. Four females dived exclusively during the day, 2 individuals dived exclusively during the night and the remaining 3 individuals exhibited no diel pattern (Fig. 2).
The multivariate analysis revealed 2 factors from the PCA that explained $82.16 \%$ of the variance and therefore were used for the subsequent HCA. Dive depth, dive rate, and mass explained most of the variance in factor 1. Factor 2 was driven by bottom time, descent and ascent rate (Table 3 ). The HCA identified 3 distinct groups of sea lions; the maximum Euclidean distance for a group to be considered was 1.07 based on the cluster tree produced by the HCA. Taking into account diving behaviour characteristics, groups were classified as (1) shallow divers, (2) deep divers and (3) bottom divers (Fig. 3).

Females in Group 1 (shallow divers: CAAF05, CAAF06) had the shallowest mean dive depths $(44.8 \pm 21.6$ and $46.3 \pm$ $18.6 \mathrm{~m}$ respectively), shortest mean dive duration $(2.94 \pm 1.17$ and $2.94 \pm 1.16 \mathrm{~min}$ respectively) and highest mean dive rate $\left(13.5 \pm 6.1\right.$ and $11.4 \pm 4.51$ dives $\mathrm{h}^{-1}$ respectively) of all females. They were also the smallest (55 and $62 \mathrm{~kg}$ respectively), primarily dove at night and spent on average $60.9 \%$ of their time at sea diving.

Females in Group 2 (deep divers: CAAF01, CAAF02, CAAF03, CAAF09) had the deepest mean dive depths (range $=101.8$ to $114.6 \mathrm{~m}$ ), shortest mean bottom time (range $=1.1$ to $1.5 \mathrm{~min}$ ), lowest mean dive rate (range $=$ 6.3 to 8.4 dives $\mathrm{h}^{-1}$ ) and lowest proportion of IDZ dives (similar depths on consecutive dives) (31.3 to 65.6\%) of all females in the study, except 1 female in Group 3 (CAAF11, deepest mean depth $=149 \mathrm{~m}$ and shortest mean dive rate $=5.2$ dives $h^{-1}$ ). These sea lions dived predominantly during the day and spent an average of $44.1 \%$ of their time at sea diving.

Lastly, females in Group 3 (bottom divers: CAAF08, CAAF10, CAAF11) had the longest mean bottom time 


\begin{tabular}{|c|c|}
\hline 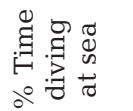 & 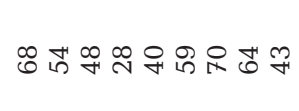 \\
\hline$\circ \stackrel{N}{\mathrm{G}}$ & 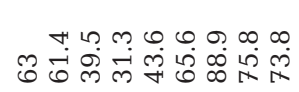 \\
\hline 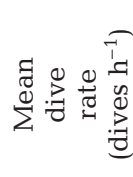 & 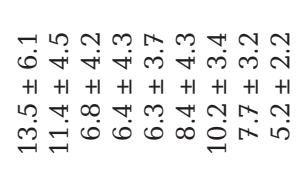 \\
\hline 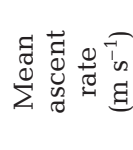 & 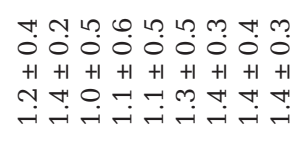 \\
\hline 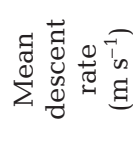 & 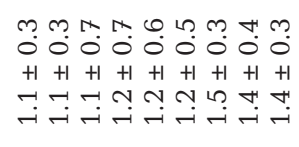 \\
\hline 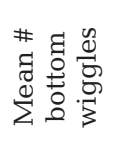 & 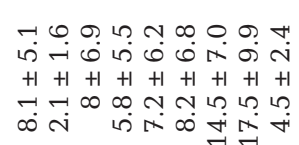 \\
\hline 急 & 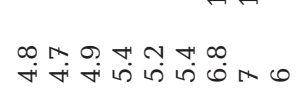 \\
\hline 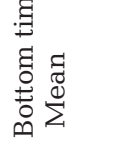 & 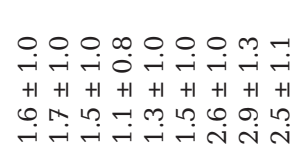 \\
\hline 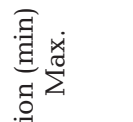 & 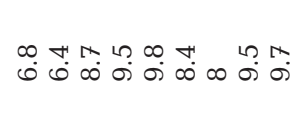 \\
\hline 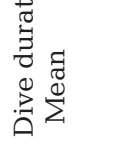 & 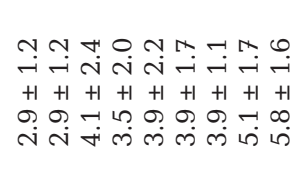 \\
\hline g్ $\sum^{\dot{x}}$ & 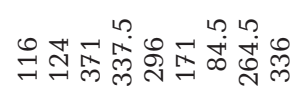 \\
\hline 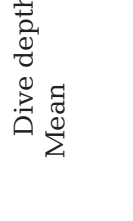 & 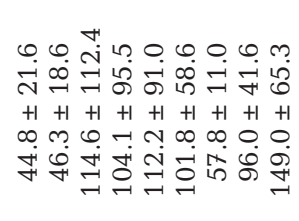 \\
\hline 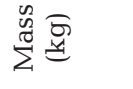 & 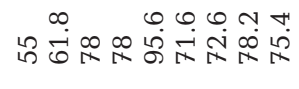 \\
\hline 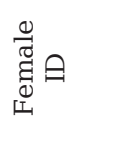 & 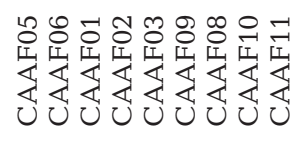 \\
\hline 党焉 & 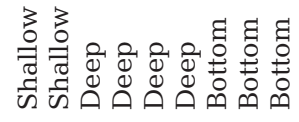 \\
\hline
\end{tabular}
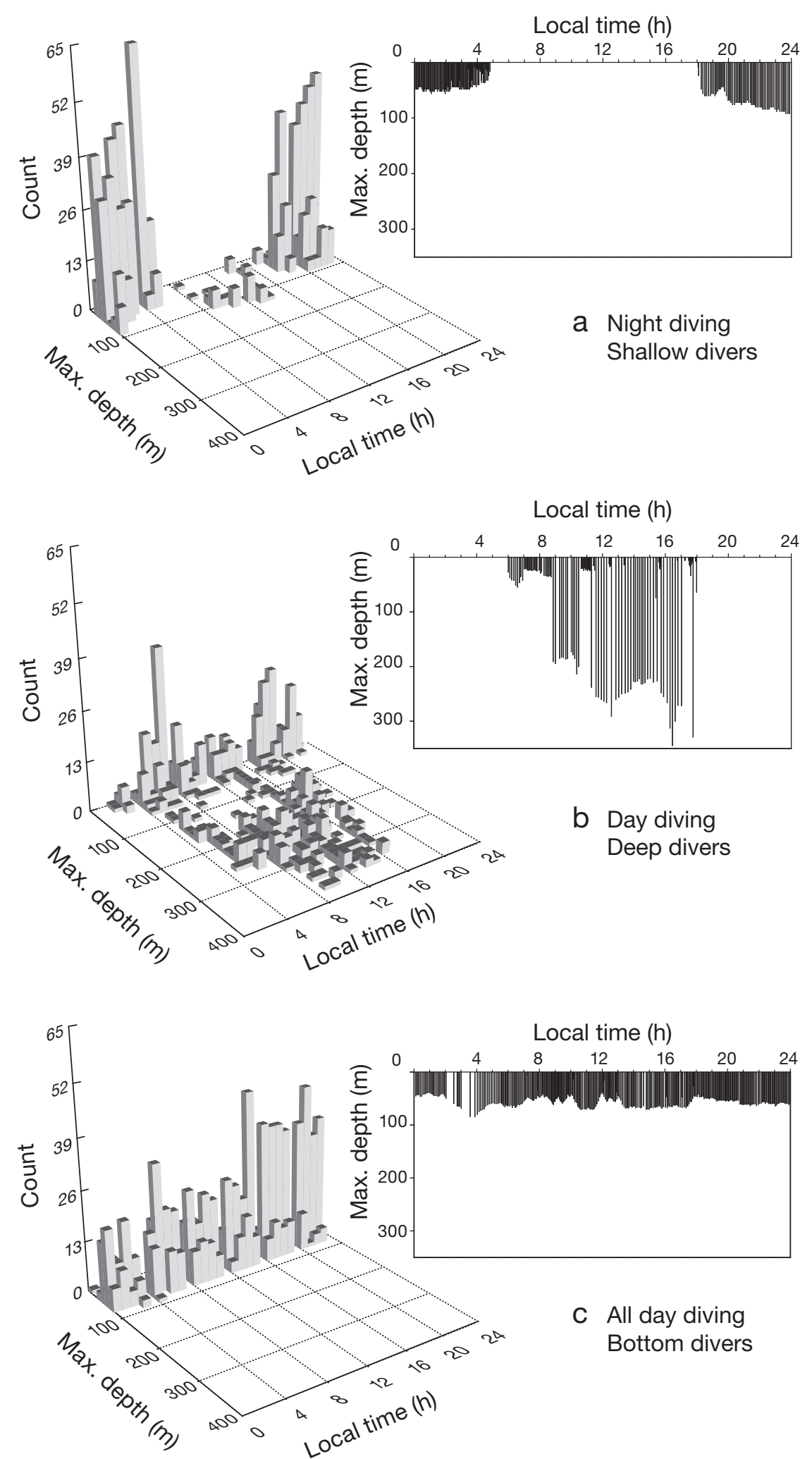

Fig. 2. Zalophus wollebaeki. Left: number of dives by depth and time of day; right: dive profiles of females from Caamaño Islet, March 2005. (a) Night diving, shallow divers group (CAAF06); (b) day diving, deep divers group (CAAF01); and (c) all day diving, bottom divers group (CAAF08) 
Table 3. Zalophus wollebaeki. PCA rotated loading matrix (SYSTAT 10.2) for dive parameters used in the diving behaviour analysis of 9 females from Caamaño Islet during March 2005. In bold are loadings for the diving variables that contributed the most for Factors 1 and 2

\begin{tabular}{|lcc|}
\hline Dive parameter & $\begin{array}{c}\text { Factor 1 } \\
(41.78 \%)\end{array}$ & $\begin{array}{r}\text { Factor 2 } \\
(40.38 \%)\end{array}$ \\
\hline Mean dive depth & $\mathbf{0 . 9 5 7}$ & -0.018 \\
Mean dive duration & 0.720 & 0.611 \\
Mean bottom time & 0.000 & $\mathbf{0 . 9 8 1}$ \\
Mean \# bottom wiggles & 0.007 & 0.654 \\
Mass & $\mathbf{0 . 8 4 7}$ & -0.044 \\
Mean descent rate & 0.363 & $\mathbf{0 . 8 7 1}$ \\
Mean ascent rate & -0.296 & $\mathbf{0 . 8 4 0}$ \\
Mean dive rate & $\mathbf{- 0 . 9 8 5}$ & 0.011 \\
\hline
\end{tabular}

(2.5 to $2.9 \mathrm{~min}$ ), longest mean dive duration (3.9 to $5.8 \mathrm{~min})$, highest mean ascent and descent rates (1.4 and 1.4 to $1.5 \mathrm{~m} \mathrm{~s}^{-1}$ respectively) and highest proportion of IDZ dives (73.8 to $88.9 \%$ ) of all females. These sea lions dived at all times of day and spent an average of $59.2 \%$ of their time at sea diving (Table 2, Fig. 2).

Consistent with the different diving depths, the 3 diving groups showed spatial segregation in their foraging locations as observed from their ARGOS positions (Fig. 4). Shallow divers foraged coastally south of Santa Cruz Island, staying within the $100 \mathrm{~m}$ isobath. The foraging range of deep divers was broader and the most widespread, comprising deeper waters over the 200 and $500 \mathrm{~m}$ isobaths between Santa Cruz, Isabela, Floreana and Santa Fe Islands. Bottom divers utilized

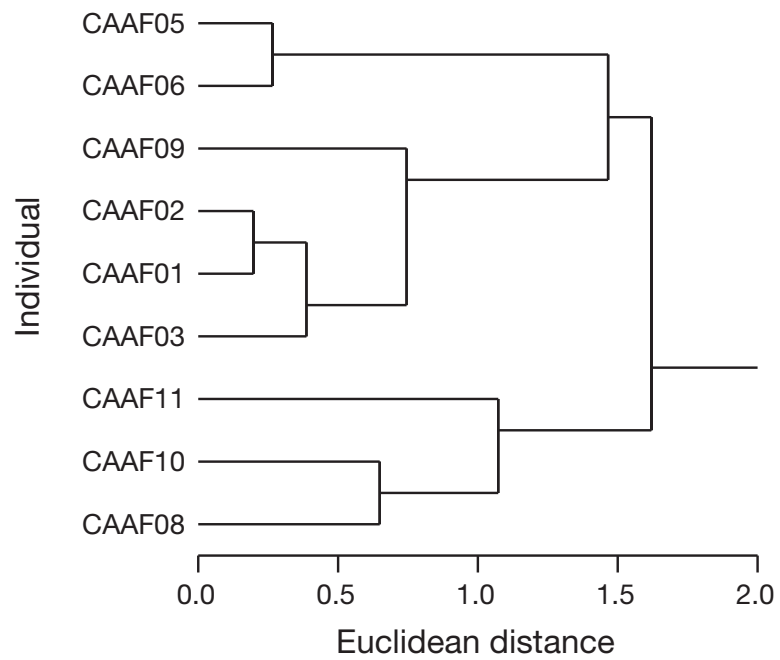

Fig. 3. Zalophus wollebaeki. Cluster tree (SYSTAT 10.2) of dive parameters from 9 females, Caamaño Islet, March 2005, showing 3 distinct groups. Euclidean distance considered for clustering was 1.07, based on the unique shared characteristics of each group the southwest waters between Santa Cruz and Isabela Islands, staying within the $200 \mathrm{~m}$ isobath. Dive depth, dive duration and trip duration from the rookery were all greater in Caamaño Islet (this study) vs. Fernandina Island (Kooyman \& Trillmich 1986) sea lions. Additionally, sea lions from Fernandina exhibited similar diving behaviour between them (Kooyman \& Trillmich 1986), possibly exhibiting one diving strategy compared to the 3 strategies found in this study (Table 4).

\section{DISCUSSION}

\section{Diving behaviour and foraging strategies}

Different modes of marine predator foraging patterns or strategies (epipelagic, mesopelagic and benthic) (Costa et al. 2004) are typically associated with different geographic regions or habitats. Rarely are all 3 foraging patterns observed in one population, one location, or one sex and age group. Most species tend to exhibit one foraging pattern exclusively. For example, king penguins from Crozet Island feed mesopelagically (Bost et al. 1997). Blue-eyed shags Phalacrocorax atriceps, Australian, New Zealand and Southern sea lions forage almost exclusively on the benthos (Croxall et al. 1991, Thompson et al. 1998, Costa \& Gales 2000, 2003). California sea lions in California and Antarctic fur seals at South Georgia Island forage epipelagically (Feldkamp et al. 1989, Boyd \& Croxall 1992). Some species like female northern fur seals Callorhinus ursinus (Goebel et al. 1991), rockhopper penguins Eudyptes chrysocome (Tremblay \& Cherel 2000) and Gentoo penguins Pygoscelis papua (Williams et al. 1992) employ 2 foraging patterns at the same location, diving either epipelagically or benthically.

Foraging patterns of species also vary geographically. Antarctic fur seals from South Georgia Island feed epipelagically on krill (Boyd \& Croxall 1992), whereas near Kerguelen Island they feed on mesopelagic myctophid fish (Cherel et al. 1996). Staniland et al. (2004) identified 4 categories of trip durations in female Antarctic fur seals Arctocephalus gazella depending on the location of foraging. To our knowledge this is the first time any sea lion species of the same sex and age class has been reported to exhibit 3 foraging patterns or strategies in one geographic area, classified as shallow, deep and bottom divers.

Shallow divers most likely dive on the shallow benthos, but they also presented some epipelagic dives during the study period. A bimodal distribution of bottom time frequencies with peaks at a short and longer bottom time reflects 2 dive types in this group. Dives with short bottom time and shallow depth reflect epipelagic dives and dives with longer bottom times 


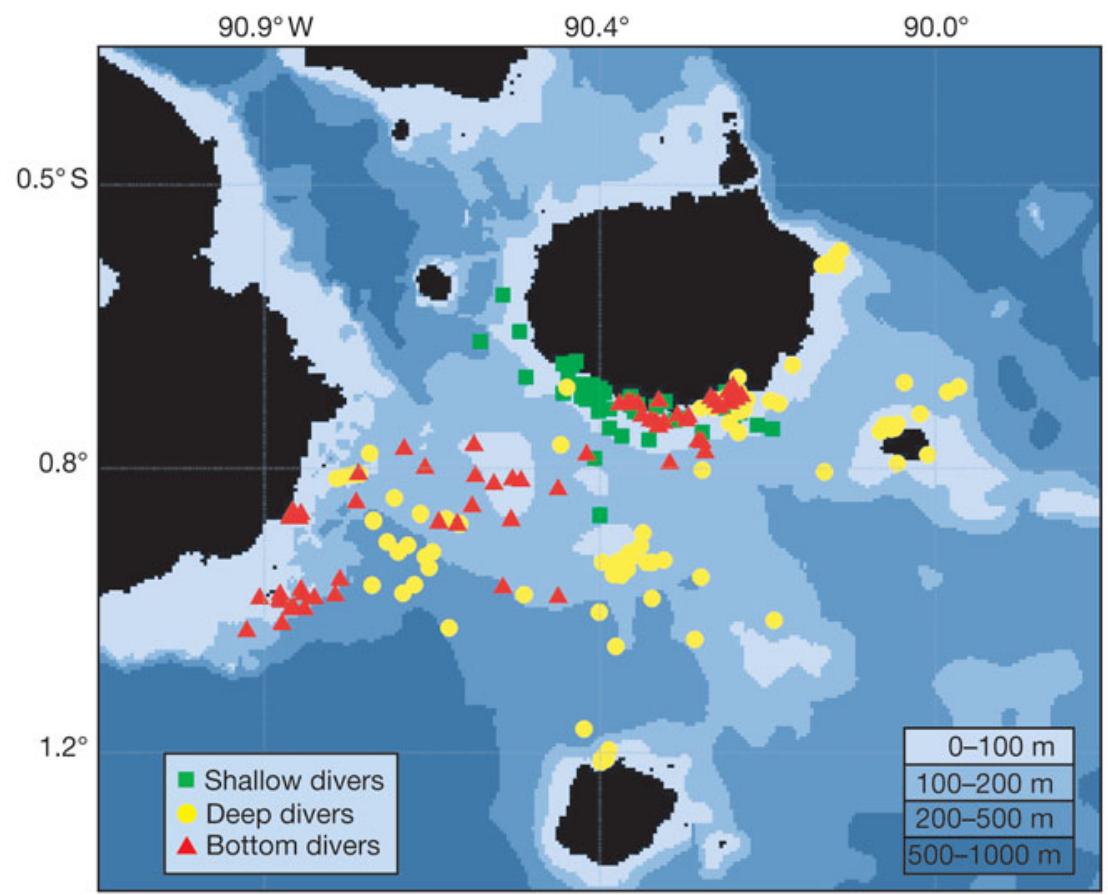

Fig. 4. Zalophus wollebaeki. Satellite locations from 9 females instrumented at Caamaño Islet, March 2005. Different colors/shapes show spatial segregation of 3 diver type groups
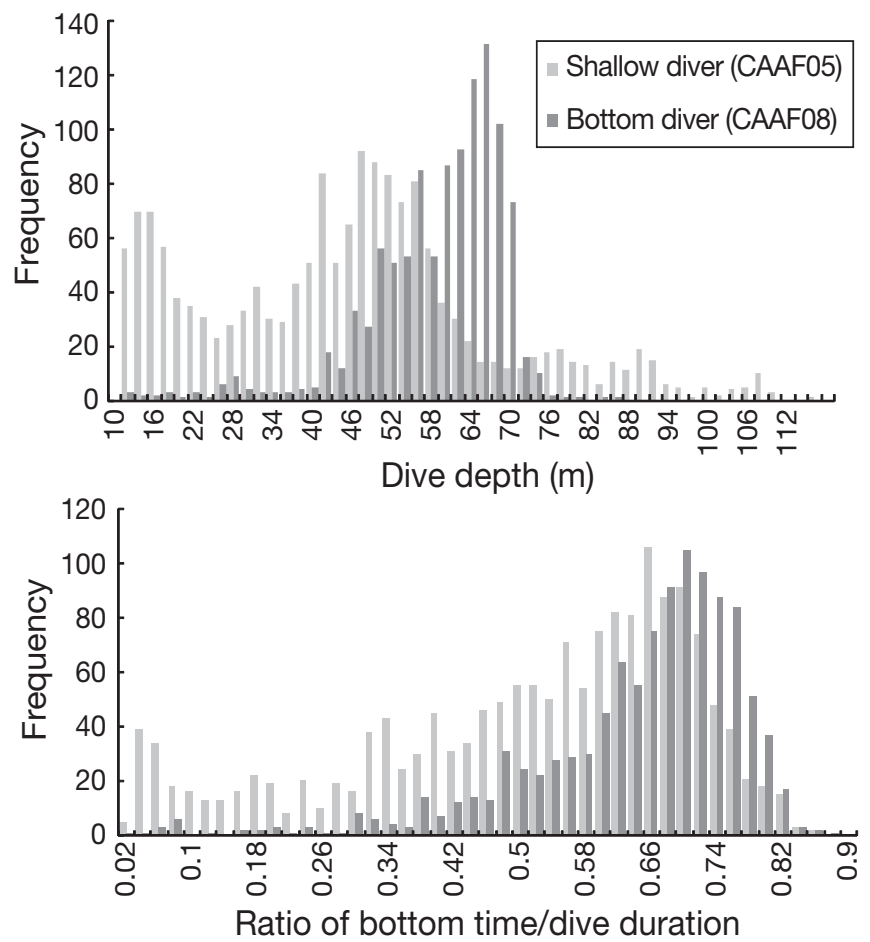

Fig. 5. Zalophus wollebaeki. Frequency distribution of dive depth $(\mathrm{m})$ and ratio of bottom time/dive duration for 2 females, a shallow diver (CAAF05) and a benthic diver (CAAF08), showing shallow epipelagic dives (low bottom time/dive duration) in the shallow diver and deeper benthic dives (higher bottom time/dive duration) in the bottom diver and deeper depths could indicate benthic dives. When compared to sea lions from the bottom divers group, the presence of 2 dive types is more evident (Fig. 5). Because shallow divers dived mostly at night and in characteristically shallow areas close to the shoreline, they likely fed on vertically migrating prey. Dolphins of New Zealand foraging at night were found to feed on the deep scattering layer as it came up along the shore (Benoit-Bird et al. 2004).

The deep divers presented characteristically deep dives, and had the lowest percentage of consecutive dives to the same IDZ, indicating that they were not likely feeding on the benthos. Some dives were most likely mesopelagic this group exhibited the highest percentage of dives deeper than $200 \mathrm{~m}$ $(15 \%)$, over water of $500 \mathrm{~m}$ depth compared to the other groups. Although the absolute depth and durations differed, general diving patterns are similar to those of other mesopelagic predators such as king penguins and northern elephant seals (LeBoeuf et al. 1986, Kooyman et al. 1992).

Lastly, the behaviour of bottom divers was consistent with benthic foraging. These sea lions had the highest ascent and descent rates, longest bottom times, and greatest percentage of consecutive dives to the same IDZ (Tremblay \& Cherel 2000). Dives were similar to the benthic dives observed in Australian, New Zealand and Southern sea lions (Thompson et al. 1998, Costa \& Gales 2000, 2003). Even though benthic dives were found in other groups as well, the 'bottom divers' classification relies on the fact that these sea lions spent most of their dive time at the bottom, as observed in their bottom time duration and descent and ascent rates.

It is important to indicate that each of the 3 groups of diving patterns was described with only a very small number of individuals. While this only allows general conclusions to be drawn, it is interesting to note that dive types found in these groups are consistent with prey species found in the diet of the Galapagos sea lion. These include epipelagic Clupeids, mesopelagic Myctophids found in deep waters (200 to $1000 \mathrm{~m}$ ), shallow and deep benthic Serranids, and shallow benthic Mugilids (0 to $120 \mathrm{~m}$ ) among others (Salazar 2005). This also suggests that frequency of each diving pattern may be high in the population since rare events are very unlikely discovered with small samples.

Individualized foraging specializations might be expected to occur more frequently in apex predators (Estes 
et al. 2003) such as the Galapagos sea lion. Individual specialization observed in this study could result from intraspecific competition due to seasonal changes in prey resources. Intraspecific competition resulting in the exploitation of different prey types and niche separation was found in the sea otter Enhydra lutris (Estes et al. 2003, Tinker et al. 2007). Ecological prerequisites of foraging specializations stated by Estes et al. (2003) include weak interspecific competition coupled with strong intraspecific competition for limited resources. Prey resources were likely to be limited during our study as it was conducted during the warm season characterized by reduced upwelling and lower productivity. Although we lack information about other species like sharks and dolphins that may target similar prey, sea lions in Caamaño Islet are the only pinniped present and no other pinnipeds are found around their foraging areas, suggesting weak interspecific competition.

Variability in the sea lions' diving behaviour can also be explained by the mass range of individuals used in this study (55 to $95.6 \mathrm{~kg}$ ). Sea lions in the shallow divers group were the smallest and exhibited the shallowest dives, foraging coastally. The size of an individual influences its physiological capabilities, which in turn limits its diving behaviour. A smaller individual has proportionally lower oxygen storage capacity for a dive, causing shorter duration aerobic dives (Costa et al. 2004, Weise \& Costa 2007). The diving behaviour of the shallow divers group appears to have an ontogenetic component given that their diving capacity could be constrained by body size. The other 2 groups do not seem to be influenced by body size; their mass varied with no particular pattern across both groups (Fig. 6).

Variability in diving behaviour could have also been influenced by pup age, which influences the mother's trip duration, affecting, in turn, her dive behaviour. Although all instrumented females were observed with small (by mass) pups, the pups could have differed in age. Growth of young in this species varies widely,

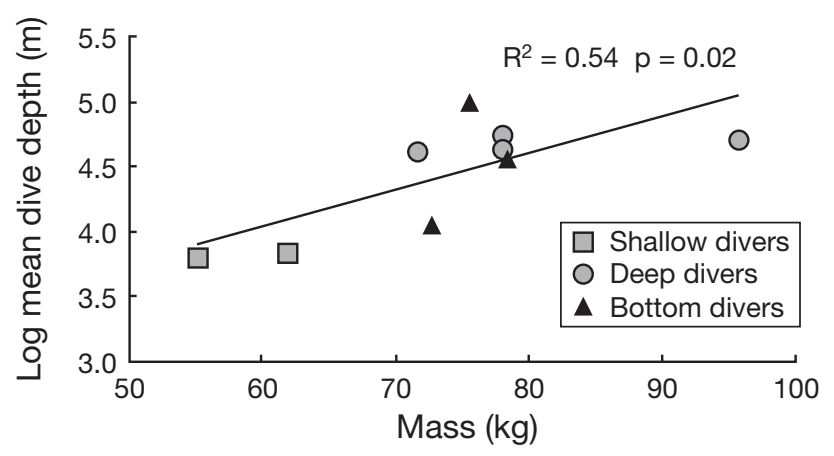

Fig. 6. Zalophus wollebaeki. Linear regression of mass (kg) vs. log-transformed mean dive depth $(\mathrm{m})$ of 9 females instrumented at Caamaño Islet, March 2005, showing a significant relationship $\left(\mathrm{R}^{2}=0.54, \mathrm{p}=0.02\right)$ making age classification very difficult (F. Trillmich pers. comm.). Unfortunately, we did not capture pups and thus lack information regarding their sex and/or age.

\section{Foraging trips}

Female Galapagos sea lions spend more time away from their pups ( 2.5 to $8 \mathrm{~d}$ ) than the $21 \mathrm{~h}$ to $5 \mathrm{~d}$ reported for other sea lions species (Feldkamp et al. 1989, Merrick \& Loughlin 1997, Thompson et al. 1998, Costa \& Gales 2000, 2003, Kuhn 2006). As these females were lactating, their pups fasted longer than those of other species, indicating that these pups may face higher nutritional stress. Longer trips are in part caused by the prospensity of Galapagos sea lion females to haul out at locations other than their rookery, which to our knowledge has only been reported for one other sea lion species, the South American sea lion (Thompson et al. 1998). The necessity to haul out at other areas could be caused by shark predation risk and thermoregulatory energetic costs. It is energetically expensive to swim to shore but these factors might make it more expensive to remain at sea, as hypothesized by Thompson et al. (1998). Longer trip durations from the rookery indicate that females have to spend longer times at sea to locate food and meet energy requirements, causing them to haul out at areas away from their pups. This creates a conflict between continuing to forage and returning to the rookery to suckle their pup (Costa 2008). Longer fasting durations for pups influence their growth, survival rates, maternal dependence and, ultimately, population trends. Galapagos sea lion populations from the southern central archipelago may increase slowly or decrease quickly, as seen during El Niño events (Trillmich \& Limberger 1985), as a result of pups having to sustain long fasting periods.

Boyd et al. (1997) showed that fur seals with attached devices increased the duration of their foraging trips by $33.8 \%$ compared to those without them. The mass of these devices represented $0.62 \%$ of the total mass of the individual. In our study the total mass of the attached devices represented only one-third of the percentage of total body mass they represented in Boyd et al.'s study, that is, $0.23 \%$ of the sea lion's mass in this study. Devices used in this study also had a lower profile than the ones used in Boyd et al.'s study. Given that the 2 main components (mass and profile) potentially affecting the sea lions' behaviour were smaller that in Boyd et al.'s study, we believe the effect of attached devices on our sea lions' behaviour was small and that our results are representative of the natural behaviour of these individuals. 


\section{Comparison of diving behaviour studies}

Two studies have been conducted on Zalophus wollebaeki diving behaviour, one by Kooyman \& Trillmich (1986) and the present research. They differ in geographic location, surrounding bathymetry and season. Kooyman \& Trillmich's (1986) study was conducted on the northwestern region of the Galapagos archipelago at Fernandina Island, the youngest and westernmost island of the Galapagos. The continental shelf is almost non-existent on its western side. In contrast, we performed our research in the central region, at Caamaño Islet, surrounded by an extensive shelf and broad central underwater plateau accessible to sea lions breeding at this colony. The former study took place during the dry season (October to November 1980), while our study was carried out during the wet season (March 2005). The wet season is characterized by lower upwelling, warmer water temperatures, reduced productivity and consequently prey abundance (Pak \& Zanveld 1973, Feldman 1986). Furthermore, Z. wollebaeki at Fernandina Island coexist with Galapagos fur seals Arctocephalus galapagoensis, whereas sea lions at Caamaño Islet are the only pinniped present.

Although the Kooyman \& Trillmich (1986) study had a smaller sample size $(n=4)$, was carried out over $20 \mathrm{yr}$ ago (different devices used) and during a different season, the contrasting results suggest that sea lions may forage differently at different areas of the Galapagos Archipelago. Diet results from Dellinger \& Trillmich (1999) support this suggestion, showing that sea lions at the west part of the archipelago fed almost exclusively on sardines, compared to Salazar's (2005) results which showed that clupeids, myctophids, serranids and mugilids, among others, are present in the diet of sea lions from the central part of the archipelago. Differing oceanographic and bathymetric features among sites influence the presence of distinct prey. Furthermore, possible competition with sympatric Galapagos fur seals Arctocephalus galapagoensis at Fernandina

Table 4. Comparison of Galapagos sea lion dive behaviour in this study with Kooyman \& Trillmich (1986). Mean dive duration $( \pm$ SD) for this study is presented

\begin{tabular}{|lcc|}
\hline & Kooyman \& Trillmich (1986) & This study \\
\hline Date/season & Oct-Nov 1980, dry season & Mar 2005, wet season \\
Location & Fernandina Island & Caamaño Islet \\
Sample size & 4 females & 9 females \\
Mean dive depth (m) & Similar, 37 or 38 & Variable, 45-149 \\
Max. dive depth (m) & $115-186$ & $84.5-371$ \\
Max. dive duration (min) & 5 or 6 & $6.4-9.8$ \\
Mean dive duration (min) & $<2$ & $4 \pm 0.9$ \\
Dive rate (dives $\mathrm{h}^{-1}$ ) & $5-13$ & $5-13.5$ \\
Time of day diving & Daylight & Daylight, night \& all day \\
\hline
\end{tabular}

Island could also be driving the specialized diet found in Zalophus wollebaeki at this site.

\section{Implications of individual specialization and management}

Individual specialization has implications for demographic, ecological and evolutionary dynamics. Specialization is expected to be higher in environments with fewer competing species (Bolnick et al. 2003) and intraspecific competition is diversifying (Roughgarden 1972). Our results support these statements, showing individual specialization as 3 distinct diving behaviours at Caamaño Islet, an area where sea lions are the only pinniped present. Further, populations with individual specialists may be open to future evolutionary diversification (Rosenzweig 1978, Lomnicki \& Ombach 1984, Doebeli 1996). Individual specialization can also produce a delayed response to fluctuations in prey availability (Werner et al. 1981). This might explain why the Galapagos sea lion population, particularly in the central area of the archipelago (which includes this study location), appears to be so sensitive to El Niño events, when prey availability is significantly diminished (Trillmich \& Limberger 1985).

Furthermore, because individual specialization is diversifying, if the high degree of individual specialization shown in these Galapagos sea lions persists through time, this population would be of great importance as it holds vast evolutionary potential, which could, in the future, increase the great diversity that already characterizes this archipelago. Galapagos sea lions are a vulnerable species (Seal Specialist Group 1996) with a fluctuating population (Trillmich \& Limberger 1985). Not only breeding but also foraging and other terrestrial habitats require protection for the species to survive.

In this study we determined for the first time the marine and terrestrial habitat utilization of Galapagos sea lions inhabiting the densest area of its population, using satellite telemetry. The foraging range of these individuals is wide and is situated within a commercially exploited area. Terrestrial habitat use is broad as well. Female sea lions used several haul-out areas other than their breeding rookery. These areas included Islas Plazas and Las Palmas in Santa Cruz Island, Los Cuatro Hermanos Islets, Tortuga Island, Santa Fe Island, Floreana Island and Punta Veintimilla at Isabela Island (Fig. 1). Taking into consideration the sea lions' wide foraging range, management plans should 
also consider protecting a wider marine area in contrast to only the immediate area around the breeding rookery.

The fact that individuals adopt a range of strategies, hunting prey in epipelagic, mesopelagic and benthic environments, suggests that they do not have a strong, reliable prey resource. Interactions with fisheries represent a great threat to the species, particularly because the number of registered fishers in Galapagos has shown a consistent increase over time (Baine et al. 2007) and some of the sea lion prey species are targeted by fisheries. The identification of distinct foraging strategies with distinct geographic and depth zones found among this population can be incorporated into new regulations to manage spatial and temporal aspects of the local fishing effort. That is, knowing the most frequented depths and areas in which sea lions dive, a regulation can be implemented to avoid fishing at those particular depths around these areas. Of particular interest are the areas around Santa Cruz Island from Isla Sin Nombre to Islas Plazas, around Santa Fe Island within the $100 \mathrm{~m}$ isobaths and waters between Santa Cruz, Floreana and Isabela Islands below $0^{\circ} 40^{\prime} \mathrm{S}$ and within the $500 \mathrm{~m}$ isobath.

Lastly, to better understand the Galapagos sea lions' habitat utilization and diving behaviour, further studies should be performed in different seasons and with larger sample sizes to determine if the distinct foraging strategies and habitat utilization found in this study continue throughout the year, or if seasonal and resource changes generate a behavioural and/or habitat utilization change in the population. If the latter is the case, management strategies and regulations to alleviate negative effects on both sea lions and fishermen can be imposed seasonally. Similar studies on different demographic groups such as males and juveniles will contribute greatly to understanding the behaviour of the population as a whole. Further studies at different sites (e.g. San Cristobal and Floreana Islands) will allow for better determination of sea lion habitat utilization and foraging range within the population's densest area. Demography and diet studies should be continued to monitor population status and fisheries interactions, particularly during El Niño and La Niña years.

Acknowledgements. We thank the TOPP (Tagging of Pacific Pelagics) Program supported by the Sloan, Packard and Moore Foundations for funding support, as well as the ONR, UC MEXUS and CONACYT. We thank The Charles Darwin Foundation and Parque Nacional Galapagos for their logistics and fieldwork support. We also thank P. Howorth and the volunteers from the Marine Mammal Center in Santa Barbara. Thanks to E. Stetson, A. Parás, B. McDonald, D. Páez, C. Martínez and volunteers from the Darwin Station for their help in the field. Special thanks to F. Trillmich for his insightful comments on this manuscript and the Costa lab at UCSC especially S. Simmons, C. Kuhn, P. Robinson, M. Weise and A.L. Harrison for their help and support in making this work possible.

\section{LITERATURE CITED}

Baine M, Howard M, Kerr S, Edgar G, Toral V (2007) Coastal and marine resource management in the Galapagos Islands and the Archipelago of San Andres: issues, problems and opportunities. Ocean Coast Manag 50:148-173

> Benoit-Bird KJ, Würsig B, McFadden CJ (2004) Dusky dolphin (Lagenorhynchus obscurus) foraging in two different habitats: active acoustic detection of dolphins and their prey. Mar Mamm Sci 20:215-231

Blake RW (1983) Energetics of leaping in dolphins and other aquatic animals. J Mar Biol Assoc UK 63:61-70

Bolnick DI, Svanbäck R, Fordyce JA, Yang LH, Davis JM, Hulsey CD, Forister ML (2003) The ecology of individuals: incidence and implications of individual specialization. Am Nat 161:1-28

Bost CA, Georges JY, Guinet C, Cherel Y and others (1997) Foraging habitat and food intake of satellite-tracked king penguins during the austral summer at Crozet Archipelago. Mar Ecol Prog Ser 150:21-33

Boyd IL, Croxall JP (1992) Diving behavior of lactating Antarctic fur seals. Can J Zool 70:919-928

Boyd IL, McCafferty DJ, Walker TR (1997) Variation in foraging effort by lactating Antarctic fur seals: response to simulated increased foraging costs. Behav Ecol Sociobiol 40: 135-144

> Cherel Y, Guinet C, Tremblay Y (1996) Fish prey of Antarctic fur seals Arctocephalus gazella at Ile de Croy, Kerguelen. Polar Biol 17:87-90

Cooper J (1986) Diving patterns of cormorants Phalacrocoracidae. Ibis $128: 562-570$

Costa DP (2008) A conceptual model of the variation in parental attendance in response to environmental fluctuation: foraging energetics of lactating sea lions and fur seals. Aquat Conserv 17:S44-S52

Costa DP, Gales NJ (2000) Foraging energetics and diving behavior of lactating New Zealand sea lions, Phocarctos hookeri. J Exp Biol 203:3655-3665

Costa DP, Gales NJ (2003) Energetics of a benthic diver: seasonal foraging ecology of the Australian sea lion, Neophoca cinerea. Ecol Monogr 73:27-43

Costa DP, Kuhn CE, Weise MJ, Shaffer SA, Arnould JPY (2004) When does physiology limit the foraging behavior of freely diving mammals? Intl Congr Ser 1275:359-366

Croxall JP, Naito Y, Kato A, Rothery P, Briggs DR (1991) Diving patterns and performance in the Antarctic blue-eyed shag Phalacrocorax atriceps. J Zool Lond 225:177-200

Dellinger T, Trillmich F (1999) Fish prey of the sympatric Galapagos fur seals and sea lions: seasonal variation and niche separation. Can J Zool 77:1204-1216

> Doebeli M (1996) An explicit genetic model for ecological character displacement. Ecology 77:510-520

Eckert SA (2006) High-use oceanic areas for Atlantic leatherback sea turtles (Dermochelys coriacea) as identified using satellite telemetered location and dive information. Mar Biol 149:1257-1267

Estes JA, Riedman ML, Staedler MM, Tinker MT, Lyon BE (2003) Individual variation in prey selection by sea otters: patterns, causes and implications. J Anim Ecol 72:144-155

Fariña JM, Salazar S, Wallem KP, Witman JD, Ellis JC (2003) Nutrient exchanges between marine and terrestrial ecosystems: the case of the Galapagos sea lion Zalophus 
wollebaecki. J Anim Ecol 72:873-887

Feldkamp SD, DeLong RL, Antonelis GA (1989) Diving patterns of California sea lions, Zalophus californianus. Can J Zool 67:872-883

Feldman GC (1986) Patterns of phytoplankton production around the Galapagos islands, Vol 17. Springer-Verlag, Berlin

Froese R, Pauly D (eds) (2006) FishBase. www.fishbase.org

Gales NJ, Mattlin RH (1997) Summer diving behavior of lactating New Zealand sea lions, Phocarctos hookeri. Can J Zool 75:1695-1706

Goebel ME, Bengtson L, DeLong RL, Gentry RL, Loughlin TR (1991) Diving patterns and foraging locations of female northern fur seals. Fish Bull (Wash DC) 89:171-179

Heath CB (2002) California, Galapagos, and Japanese sea lions Zalophus californianus, Z. wollebaeki, and Z. japonicus. In: Perrin WF, Wursig B, Thiewissen JGM (eds) Encyclopedia of marine mammals. Academic Press, London, p 180-186

Hopkins-Murphy SR, Owens DW, Murphy TM (2003) Ecology of immature loggerheads on foraging grounds and adults in internesting habitat in the eastern Unites States. In: Bolten $A B$, Witherington $B E$ (eds) Loggerhead sea turtles. Smithsonian Institution Press, Washington, DC, p 79-92

Kooyman GL, Trillmich F (1986) Diving behavior of Galapagos sea lions. In: Gentry RL, Kooyman GL (eds) Fur seals: maternal strategies on land at and sea. Princeton University Press, Princeton, NJ, p 209-219

Kooyman GL, Cherel Y, Le Maho Y, Croxall JP, Thorson PH, Ridoux V, Kooyman CA (1992) Diving behaviour and energetics during foraging cycles in king penguins. Ecol Monogr 62:143-163

Kuhn CE (2006) Measuring feeding to understand the foraging behavior of pinnipeds. PhD thesis, University of California Santa Cruz

LeBoeuf BJ, Costa DP, Huntley AC, Kooyman GL, Davis RW (1986) Pattern and depth of dives in northern elephant seals. J Zool 208:1-7

Lomnicki A, Ombach J (1984) Resource partitioning within a single species population and population stability: a theoretical model. Theor Popul Biol 25:21-28

McGarigal K, Cushman S, Stafford S (2000) Multivariate statistics for wildlife and ecology research. Springer-Verlag, New York

McMahon CR, Bradshaw CJA, Hays GC (2007) Satellite tracking reveals unusual diving characteristics for a marine reptile, the olive ridley turtle Lepidochelys olivacea. Mar Ecol Prog Ser 329:239-252

Merrick RL, Loughlin TR (1997) Foraging behavior of adult female and young-of-the-year Steller sea lions in Alaska waters. Can J Zool 75:776-786

Pak H, Zanveld JRV (1973) The Cromwell Current on the east side of the Galapagos Islands. J Geophys Res 78:

Editorial responsibility: Rory Wilson,

Swansea, UK
$7845-7859$

Rosenzweig ML (1978) Competitive speciation. Biol J Linn Soc 10:275-289

Roughgarden J (1972) Evolution of niche width. Am Nat 106:683-718

Salazar SK (2005) Variación temporal y espacial del espectro trófico del lobo marino de Galápagos. Master's thesis, Instituto Politécnico Nacional, La Paz

Seal Specialist Group (1996) Zalophus wollebaeki. In: IUCN 2007. 2007 IUCN Red List of Threatened species. Available at: www.iucnredlist.org

Staniland IJ, Reid K, Boyd IL (2004) Comparing individual and spatial influences on foraging behavior in Antarctic fur seals Arctocephalus gazella. Mar Ecol Prog Ser 275: 263-274

> Thompson D, Dick CD, McConnell BJ, Garrett J (1998) Foraging behavior and diet of lactating female southern sea lions (Otaria flavescens) in the Falkland Islands. J Zool Lond 246:135-146

> Tinker MT, Costa DP, Estes JA, Wieringa N (2007) Individual dietary specialization and dive behaviour in the California sea otter: using archival time-depth data to detect alternative foraging strategies. Deep-Sea Res 54:330-342

Tremblay Y, Cherel Y (2000) Benthic and pelagic dives: a new foraging behavior in rockhopper penguins. Mar Ecol Prog Ser 204:257-267

> Tremblay Y, Cherel Y (2003) Geographic variation in the foraging behavior, diet and chick growth of rockhopper penguins. Mar Ecol Prog Ser 251:279-297

Trillmich F (1986) Attendance behavior of Galapagos sea lions. In: Gentry RL, Kooyman GL (eds) Fur seals: maternal strategies on land and sea. Princeton University Press, Princeton, NJ, p 196-208

Trillmich F, Limberger D (1985) Drastic effects of El Niño on Galapagos pinnipeds. Oecologia 67:19-22

Weise MJ, Costa DP (2007) Total body oxygen stores and physiological diving capacity of California sea lions as a function of sex and age. J Exp Biol 210:278-289

> Werner EE, Mittelbach GG, Hall DJ (1981) The role of foraging profitability and experience in habitat use by the bluegill sunfish. Ecology 62:116-125

Williams TD, Briggs DR, Croxall JP, Naito Y, Kato A (1992) Diving pattern and performance in relation to foraging ecology in the gentoo penguin, Pygoscelis papua. J Zool Lond 227:211-230

Williams TM (2001) Intermittent swimming by mammals: a strategy for increasing energetic efficiency during diving. Am Zool 41:166-176

Wolf JBW, Trillmich F (2007) Beyond habitat requirements: individual fine-scale site fidelity in a colony of the Galapagos sea lion (Zalophus wollebaeki) creates conditions for social structuring. Oecologia 152:553-567

Submitted: September 19, 2007; Accepted: February 22, 2008 Proofs received from author(s): June 21, 2008 